\title{
Hydroxyethyl starch 6\%, 130/0.4 vs. a balanced crystalloid solution in cardiopulmonary bypass priming: a randomized, prospective study
}

Hasan Alper Gurbuz ${ }^{1,2}$, Ahmet Baris Durukan ${ }^{1,2^{*}}$, Nevriye Salman ${ }^{3}$, Murat Tavlasoglu4 ${ }^{4}$ Elif Durukan ${ }^{5}$, Halil İbrahim Ucar ${ }^{1}$ and Cem Yorgancioglu ${ }^{1}$

\begin{abstract}
Background: Since the advent of cardiopulmonary bypass, many efforts have been made to avoid the complications related with it. Any component of the pump participates in occurrence of these adverse events, one of which is the type of prime solution. In this study, we aimed to compare the effects of $6 \%$ hydroxyethyl starch 130/0.4 with a commonly used balanced electrolyte solution on postoperative outcomes following coronary bypass surgery.

Methods: Two hundred patients undergoing elective coronary bypass surgery were prospectively studied. The patients were randomized in to two groups. First group received a balanced electrolyte solution and the second group received $6 \%$ hydoxyethyl starch $130 / 0.4$ as prime solution. The postoperative outcomes of the patients were studied.

Results: The mean age of the patients was $61.81 \pm 10.12$ in the crystalloid group whereas $61.52 \pm 9.29$ in the HES group. There were 77 male patients in crystalloid group and 74 in HES group. 6\% hydroxyethyl starch 130/0.4 did not have any detrimental effects on renal and pulmonary functions. The intensive care unit stay and postoperative hospital length of stay were shorter in hydroxyethyl starch group ( $p<0.05$ for each). Hydroxyethyl starch did not increase postoperative blood loss, amount of blood and fresh frozen plasma used, but it decreased platelet concentrate requirement. It did not have any effect on occurrence of post-coronary bypass atrial fibrillation ( $p>0.05$ ).

Conclusions: $6 \%$ hydroxyethyl starch 130/0.4 when used as a prime solution did not adversely affect postoperative outcomes including renal functions and postoperative blood transfusion following coronary bypass surgery.
\end{abstract}

Keywords: Hetastarch, Coronary artery bypass, Outcome assessment

\section{Background}

Increased number of patients are undergoing coronary artery bypass grafting (CABG) and efforts to prevent adverse events and improve outcomes are done. One of the most important problems following cardiac surgery is renal failure. Use of cardiopulmonary bypass $(\mathrm{CPB})$, blood and constituents, various drugs and infusion of large volumes of fluids influence the renal functions. Occurrence of perioperative renal impairment causes

\footnotetext{
* Correspondence: barisdurukan@yahoo.com

${ }^{1}$ Department of Cardiovascular Surgery, Medicana International Ankara Hospital, Ankara, Turkey

${ }^{2}$ Department of Biology, Hacettepe University Faculty of Science, Ankara, Turkey

Full list of author information is available at the end of the article
}

increased mortality and morbidity [1]. Modifications on every component of $\mathrm{CPB}$ are studied to decrease the risk of renal failure particularly related with $\mathrm{CPB}$ use.

Cardiopulmonary bypass priming solution and volume are of special importance since it directly affects renal functions. Hemodilution due priming volume, continuous flow pattern of $\mathrm{CPB}$, use of various drugs during $\mathrm{CPB}$ and occurrence of systemic inflammatory response syndrome (SIRS) adversely affect renal functions [2].

Hydroxyethyl starch (HES) is commonly used in current practice as a volume expander in trauma, shock, cardiac and other major surgeries and vast numbers of reports are being published with conflicting results. Still there is no consensus on the renal effects of HES solutions.

\section{Biomed Central}


In this randomized prospective study, we aimed to document the effects of $6 \%$ hydroxyethyl starch 130/0.4 on postoperative outcomes and occurrence of atrial fibrillation (AF) in patients undergoing on-pump CABG surgery.

\section{Methods}

A prospective and randomized study has been carried out. The study was approved by the "Medicana International Ankara Hospital Ethics Committee" and written informed consent was taken from every patient. The only inclusion criteria were isolated on-pump CABG procedure. Both genders were accepted. There were no age or weight restrictions. Exclusion criteria were; repeat cardiac surgery, emergent surgery, preoperative coagulation disorder, preoperative clopidogrel use, preoperative congestive heart failure, preoperative renal dysfunction (serum creatinine $>1.3 \mathrm{mg} / \mathrm{dl}$ ), preoperative hepatic dysfunction (serum aspartate/alanine amino transferase $>40 \mathrm{U} / \mathrm{l}$ ), preoperative electrolyte imbalance, history of pancreatitis and known hypersensitivity to HES. Between October 2011 and April 2012, after the inclusion and exclusion criteria were employed 200 isolated CABG cases were studied. The patients were then randomized as follows: each patient was given a number according to chronological order beginning from 1 . The odd numbered patients (n:100) were administered 6\% HES 130/0.4 in $0.9 \%$ sodium chloride (Voluven ${ }^{\circledR} \%$, Fresenius Kabi, Bad Homburg, Germany) as CPB prime solution and even numbered patients (n:100) were administered a balanced multielectrolyte solution (Isolyte- $\mathrm{M}^{\circledR}$, Eczacıbaşı-Baxter, İstanbul: dextrose monohydrate, $40 \mathrm{mEq} / \mathrm{l}$ sodium, $40 \mathrm{mEq} / \mathrm{l}$ chloride, $35 \mathrm{mEq} / \mathrm{l}$ potassium, $15 \mathrm{mEq} / \mathrm{l}$ phosphate, $20 \mathrm{mEq} / \mathrm{l}$ acetate; 400 $\mathrm{mOsm} / \mathrm{l}, 170 \mathrm{kCal} / \mathrm{l})$.

Preoperative acetylsalicylic acid $100 \mathrm{mg}$ /day was continued in all patients prior to the day of surgery. All patients were premedicated with $10 \mathrm{mg}$ of oral diazepam. Anesthesia was induced with etomidate $2 \mathrm{mg} / \mathrm{kg}$, fentanyl $1 \mu \mathrm{g} / \mathrm{kg}$, vecuronium $1 \mathrm{mg} / \mathrm{kg}$; isofluorane $1 \mathrm{MAC}$ was used for anesthesia maintenance. Intraoperative arterial and central venous pressure monitorization were done.

The cardiopulmonary bypass (CPB) circuit was primed with $1,500 \mathrm{ml}$ of determined solution. In both groups 5,000 units of heparin was added. After anticoagulation with heparin $(300 \mathrm{U} / \mathrm{kg})$, activated clotting time (ACT) was kept over 400 seconds. CPB was established using a roller pump with a membrane oxygenator (Dideco Compactflo Evo, Sorin Group, Mirandola Modena, Italy). The average flow rate varied from 2.3 to $2.4 \mathrm{l} / \mathrm{min} / \mathrm{m}^{2}$. Surgery was performed under mild hypothermia $\left(33^{\circ} \mathrm{C}\right)$. Mean arterial pressure was kept between 45 to $70 \mathrm{~mm} \mathrm{Hg}$. All patients were rewarmed to $37^{\circ} \mathrm{C}$ (nasopharyngeal temperature) before weaning from $\mathrm{CPB}$. Heparin was neutralized with 1:1 protamine sulfate.
Cold $\left(4-8^{\circ} \mathrm{C}\right)$ blood cardioplegia of $1000 \mathrm{ml}(25 \mathrm{mEq} / \mathrm{l}$ potassium) was administered after aortic cross clamping, and $500 \mathrm{ml}$ repeat doses were given every 15 to 20 minutes (antegrade and from venous bypass grafts, retrograde in patients with left main coronary disease). Terminal warm blood cardioplegia $\left(36-37^{\circ} \mathrm{C}\right)$ was given prior to aortic clamp release.

The operation room temperature was kept at $20-21^{\circ} \mathrm{C}$.

In postoperative period rate of fluid infusions were adjusted according to hemodynamic measurements. Central venous pressure was maintained between 8-12 $\mathrm{mm} \mathrm{Hg}$.

Packed red blood cell was given if the hematocrit level fell below 25\%. Fresh frozen plasma and platelet concentrates were administered in cases of documented postoperative coagulation abnormalities (international normalized ratio $>1.5$, activated partial thromboplastin time $>60 \mathrm{~s}$ and platelet count $<80,000 / \mathrm{mm}^{3}$ ) or suspected postoperative platelet dysfunction and factor deficiency.

The decision for re-exploration for hemorrhage was made when $200 \mathrm{ml} /$ hour of drainage was documented on two consecutive hours despite measures taken or more than $300 \mathrm{ml} /$ hour drainage.

On postoperative day 1 , all patients were administered metoprolol (50 mg/day) or carvedilol (3.125-6.25 mg/day) and $\mathrm{N}$-acetylcysteine (oral: creatinine $<1.3 \mathrm{mg} / \mathrm{dl}$; intravenous: creatinine $>1.3 \mathrm{mg} / \mathrm{dl}$ ) and continued. All patients were routinely administered low molecular weight heparin in prophylactic dose.

Atrial fibrillation was diagnosed based on electrocardiogram. All patients were ECG monitored continuously during the intensive care unit (ICU) stay and for the first 24 hours in the ward. Soon ECG was immediately performed in cases of irregular pulse, palpitation or symptoms related with possible AF.

In cases with AF, if required intravenous metoprolol was administered for heart rate control. For rhythm control, intravenous amiodarone was administered as intravenous $300 \mathrm{mg}$ loading dose in 1 hour, followed by $900 \mathrm{mg}$ in 24 hours and followed by oral amiodarone $200 \mathrm{mg}$ three times a day. In refractory cases $450 \mathrm{mg}$ additional intravenous infusion was given in 12 hours period. If no response was noted after 48 hours, electrical cardioversion was employed. Low molecular weight heparin dosage was switched to therapeutic interval. In cases of permanent AF development, oral warfarin was administered.

Primary outcome variables included mean time to extubation, ICU and postoperative hospital length of stay, incidence of renal dysfunction (based on the finding that peak creatinine value was 1.5 or greater times the preoperative value), postoperative stroke, postoperative total amount of blood loss, postoperative exploration for hemorrhage, number of used blood and blood products and in hospital mortality. 


\section{Statistical analysis}

Statistical analyses were performed using SPSS software for Windows version 17.0 (Statistical Package for the Social Sciences Inc, Chicago, IL, USA). Continuous variables were expressed as 'mean values \pm standard deviation (SD)'. Categorical variables were expressed as number and percentages. Demographic characteristics and outcomes of the groups were compared using "independent samples $t$-test" for continuous variables, and, 'chi-square test' and 'Fisher's exact test' for categorical variables. Statistical significance was set as ' $\mathrm{p}<0.05$ '.

\section{Results}

The mean age of the patients was $61.81 \pm 10.12$ in the crystalloid group whereas $61.52 \pm 9.29$ in the HES group $(p>0.05)$. There were 77 male patients in crystalloid group and 74 in HES group $(p>0.05)$. Preoperative demographic findings and intraoperative characteristics of the patients are given in Table 1.

Table 1 Comparison of the two groups by preoperative and intraoperative characteristics

\begin{tabular}{|c|c|c|c|}
\hline \multirow[t]{2}{*}{ Factor } & \multirow{2}{*}{$\begin{array}{c}\left.\text { Isolyte-M }^{(}\right) \\
\text {group (n:100) } \\
\text { Mean } \pm \text { SD }\end{array}$} & \multirow{2}{*}{$\begin{array}{c}\text { Voluven }^{\circledR} 6 \% \\
\text { group (n:100) } \\
\text { Mean } \pm \text { SD }\end{array}$} & \multirow[t]{2}{*}{ p value* } \\
\hline & & & \\
\hline Age & $61.81 \pm 10.12$ & $61.52 \pm 9.29$ & 0.833 \\
\hline $\mathrm{BMI}\left(\mathrm{kg} / \mathrm{m}^{2}\right)$ & $27.88 \pm 3.96$ & $29.02 \pm 4.61$ & 0.063 \\
\hline LVEF (\%) & $53.72 \pm 10.81$ & $52.33 \pm 11.08$ & 0.370 \\
\hline Cross-clamp time (min) & $53.57 \pm 20.12$ & $55.58 \pm 17.22$ & 0.449 \\
\hline CPB time (min) & $79.69 \pm 27.93$ & $82.57 \pm 23.98$ & 0.435 \\
\hline \multirow[t]{2}{*}{ Graft \# } & $3.22 \pm 1.06$ & $3.10 \pm 0.90$ & 0.390 \\
\hline & $\mathrm{n}: \%$ & $\mathrm{n}: \%$ & $p$ value $e^{* *}$ \\
\hline Patient Total & 100 & 100 & \\
\hline Male sex & 77 & 74 & 0.622 \\
\hline Current/Ex-smoker & 67 & 63 & 0.553 \\
\hline Diabetes Mellitus & 46 & 42 & 0.569 \\
\hline Hypertension & 65 & 62 & 0.659 \\
\hline Dyslipidemia & 79 & 76 & 0.611 \\
\hline Preoperative $\beta$-blocker use & 40 & 47 & 0.318 \\
\hline Peripheral Arterial Disease ${ }^{a}$ & 1 & 6 & $0.118^{* * *}$ \\
\hline Stroke & - & 1 & $1.000^{* * *}$ \\
\hline Carotid Disease $^{b}$ & 7 & 5 & $0.552^{* * *}$ \\
\hline COPD/Asthma & 14 & 15 & 0.841 \\
\hline
\end{tabular}

*independent samples $t$-test.

** chi-square test.

***Fisher's exact test

${ }^{a}$ History of therapeutic vascular intervention, history of claudication, angiography/non-invasive proven peripheral arterial disease.

${ }^{b}$ History of carotid intervention or angiographic/non-invasive proven $>40 \%$ stenosis of either carotid.

BMI: body mass index, LVEF: left ventricular ejection fraction.

CPB: cardiopulmonary bypass, COPD: chronic obstructive pulmonary disease.
There was not a statistically significant difference when intubation times, postoperative drainage, amount of red blood cell and fresh frozen plasma used and postoperative adverse events (renal failure, stroke, mortality) were compared. Number of platelet concentrate used was lower in the HES group $(\mathrm{p}<0.05)$. Postoperative ICU and postoperative hospital length of stay were shorter in HES group $(\mathrm{p}<0.05)$ (Table 2$)$. No mortality was noted during the study period.

Atrial fibrillation incidence was 19\% in HES group whereas $15 \%$ in crystalloid group ( $p>0.05)$.

\section{Discussion}

Coronary bypass surgery is the most frequently performed cardiac operation worldwide and modifications are made in order to maintain more reasonable results [3]. Various improvements are recorded on surgical techniques, $\mathrm{CPB}$ devices, drugs and perioperative management. Postoperative outcomes especially renal functions are very important in these patients due to the direct relation between mortality and morbidity. In this report, we also hypothesized to document

Table 2 Comparison of the two groups by postoperative variables

\begin{tabular}{|c|c|c|c|}
\hline & $\begin{array}{l}\text { Isolyte- }^{(\mathbb{}} \\
\text { group } \\
\text { Mean } \pm S D\end{array}$ & $\begin{array}{c}\text { Voluven }^{\circledR} 6 \% \\
\text { group } \\
\text { Mean } \pm \text { SD }\end{array}$ & p value ${ }^{*}$ \\
\hline ICU intubation time, hours & $10.38 \pm 9.04$ & $9.38 \pm 2.64$ & 0.290 \\
\hline \multicolumn{4}{|l|}{ Length Of Stay } \\
\hline ICU, hours & $47.93 \pm 12.01$ & $45.25 \pm 5.86$ & 0.046 \\
\hline Postoperative, days & $6.14 \pm 2.55$ & $5.47 \pm 1.20$ & 0.019 \\
\hline $\begin{array}{l}\text { Drainage tubes removed, } \\
\text { hours }\end{array}$ & $36.36 \pm 10.39$ & $36.12 \pm 13.32$ & 0.886 \\
\hline $\begin{array}{l}\text { Total amount of drainage, } \\
\mathrm{ml}\end{array}$ & $741.75 \pm 448.58$ & $680.30 \pm 332.92$ & 0.273 \\
\hline Number of FFP used & $1.05 \pm 1.32$ & $1.02 \pm 1.40$ & 0.877 \\
\hline $\begin{array}{l}\text { Number of packed RBC } \\
\text { used }\end{array}$ & $1.82 \pm 1.65$ & $1.63 \pm 1.50$ & 0.397 \\
\hline \multirow[t]{2}{*}{ Number of PC used } & $0.61 \pm 1.92$ & $0.15 \pm 0.98$ & 0.035 \\
\hline & $\mathrm{n}: \%$ & $\mathrm{n}: \%$ & $p$ value $e^{* *}$ \\
\hline $\begin{array}{l}\text { Postoperative exploration } \\
\text { for hemorrhage }\end{array}$ & 2 & 5 & 0.445 \\
\hline Postoperative AF & 15 & 19 & $0.451^{* * *}$ \\
\hline Renal Dysfunction ${ }^{a}$ & 6 & 9 & 0.421 \\
\hline Postoperative Stroke & 1 & 1 & 1.000 \\
\hline
\end{tabular}

*Independent samples t-test.

** Fisher's exact test.

***chi-square test.

${ }^{\text {a }}$ defined when peak creatinine value was 1.5 or greater times the preoperative value.

ICU: intensive care unit, FFP: fresh frozen plasma.

RBC: red blood cell, PC: platelet concentrate.

AF: atrial fibrillation. 
improvements in perioperative management by using HES solutions as priming solution.

During $\mathrm{CPB}$, derangements in multiple organ systems occur, and the resultant SIRS is the main reason for postoperative morbidity and mortality. The main causes of these changes are the contact with foreign surfaces, changes in coagulation and fibrinolytic systems, activation of the complement system, hemodilution and hypothermia. Also endotoxemia and ischemia-reperfusion injury have adverse effects. Any component of CPB system has direct influence on postoperative outcomes. Two of the most important components are the type and volume of priming solution $[4,5]$.

Various types of priming solutions have been researched and employed, but today still there is no consensus on ideal priming solution in clinic use that can prevent SIRS, fluid retention and hypercoagulation. Hydroxyethyl starch is used very frequently as a priming solution in cardiovascular surgery and as a volume expanding agent in perioperative care and in trauma. Many reports were published concerning the results following HES use, but very recently some of them were retracted. This shaded the formed concept on HES solutions and created a doubtful era. Today, there is still a controversy on the effects of HES particularly on coagulation and renal functions.

Choi et al. [6] studied the effects of HES when used as a priming solution in comparison with human albumin and they did not find any difference on coagulation variables, postoperative blood loss, transfusion requirements and inflammatory response. In our study, we compared HES with a commonly used crystalloid solution and found similar results; HES did not cause detrimental results on postoperative outcomes.

Liou et al. [7] reported comparison between three different priming solutions; ringers lactate, human albumin and $\% 10$ HES. Time to extubation, ICU stay and hospital stay did not differ among the groups. The inflammatory cytokines TNF- $\alpha$, IL- $1 \beta$ and IL- 6 levels were also measured following $\mathrm{CPB}$ and no statistically significant difference was reported. There was statistically significant difference in postoperative body weight gain, HES and human albumin groups caused less weight gain compared to ringers lactate. This was because hypo-oncotic prime solutions lead to interstitial fluid expansion more than colloids. We also documented similar results, but we also studied postoperative outcomes. We did not study the inflammatory cytokines.

Kuitunen et al. [8] reported the effects of HES used for priming on coagulation and concluded that HES use increased blood loss. They revealed that less stable thrombi were formed documented with thromboelastography. They also concluded that HES in cardiac surgery may increase blood loss. In our study, we did not find any difference concerning the blood loss between the crystalloid and HES groups, HES did not adversely affect postoperative bleeding.

Tiryakioglu et al. [9] designed a similar study of prime solutions and compared ringers lactate with HES. They documented unfavorable effects of HES on renal functions, but the urea and creatinine levels were in the normal range in both groups. They found no statistical difference in amount of postoperative bleeding, time to extubation, intensive care unit stay and discharge times. They only noted statistically significant difference in net volume balance in favor of HES group. We did not document any adverse effect on renal functions.

Yap et al. [10] studied gelatin and HES as prime solutions and compared postoperative outcomes like intraocular pressure, blood profile and blood loss. They designated intraocular pressure as a marker to determine plasma oncotic pressure and they found that HES had had significant favorable results compared to gelatin. There was no difference concerning blood profile, blood loss and other postoperative outcomes.

In a meta-analysis, it was documented that use of HES did not cause any impairment in renal functions and also no difference was found considering the risk of complications, reoperation and mortality [11]. Very recently, Akkucuk et al. [12] documented their results on use of HES 130/0.4 on pediatric patients undergoing CPB and revealed no adverse effects on renal functions and other events.

In cardiac surgery, the effects of HES solutions also were studied for volume replacement in the postoperative period. The results of the studies were similar to those when HES solutions were used for priming. There were no adverse effects documented on postoperative coagulation parameters and postoperative renal functions $[13,14]$.

The effects of HES on AF can be regarded as a special issue. Atrial fibrillation is the most common rhythm disturbance following cardiac surgery and many efforts are being made to reduce the risk of occurrence of AF. It was revealed that there was a strong correlation between the $\mathrm{AF}$ and inflammation [15-17]. The anti-inflammatory effects of HES solutions have been documented $[18,19]$. In our study, we also studied the effects of HES used as a prime solution on occurrence of postoperative AF. We did not note any difference between the groups.

\section{Conclusions}

In this prospective randomized study, we did not document any difference between HES and crystalloid solutions used for $\mathrm{CPB}$ priming regarding postoperative outcomes like postoperative bleeding, renal functions and the use of blood and FFP. The number of used PC was less and the hospital length of stay and ICU stay were 
shorter in HES group. The results may differ in high risk patient groups and further studies with increased number of patients should be made particularly on patients with renal failure and coagulation disorders.

\section{Abbreviations}

CABG: Coronary artery bypass grafting; CPB: Cardiopulmonary bypass; SIRS: Systemic inflammatory response syndrome; HES: Hydroxyethyl starch; AF: Atrial fibrillation; ICU: Intensive care unit.

\section{Competing interests}

The authors declare that they have no competing interests.

\section{Authors' contributions}

GHA: study concepts, study design, definition of intellectual content, literature research, data acquisition, data analysis, manuscript preparation, manuscript editing; DAB: study concepts, study design, definition of intellectual content, literature research, data acquisition, data analysis, manuscript preparation, manuscript editing SN: definition of intellectual content, literature research, data acquisition, manuscript preparation, manuscript editing; DE: data analysis, statistical analysis, manuscript editing; TM: definition of intellectual content, data acquisition, data analysis, manuscript editing; UHI: study concepts, study design, definition of intellectual content, data acquisition, data analysis, manuscript editing; YC: study concepts, study design, definition of intellectual content manuscript preparation, manuscript editing, supervision. All authors read and approved the final manuscript.

\section{Acknowledgements}

Institution where the work was done: Medicana International Ankara Hospital, Ankara, Turkey.

\section{Author details}

'Department of Cardiovascular Surgery, Medicana International Ankara Hospital, Ankara, Turkey. ${ }^{2}$ Department of Biology, Hacettepe University Faculty of Science, Ankara, Turkey. ${ }^{3}$ Department of Anesthesiology, Medicana International Ankara Hospital, Ankara, Turkey. ${ }^{4}$ Department of Cardiovascular Surgery, Diyarbakir Military Hospital, Diyarbakir, Turkey. ${ }^{5}$ Department of Public Health, Ankara Baskent University, Ankara, Turkey.

Received: 16 February 2013 Accepted: 26 March 2013

Published: 8 April 2013

\section{References}

1. Bahar I, Akgul A, Ozatik MA, Vural KM, Demirbag AE, Boran M, Tasdemir O: Acute renal failure following open heart surgery: risk factors and prognosis. Perfusion 2005, 20:317-322.

2. Vermeer $H$, Teerenstra $S$, de Sevaux RG, van Swieten HA, Weerwind PW: The effect of hemodilution during normothermic cardiac surgery on renal physiology and function: a review. Perfusion 2008, 23:329-338.

3. Atluri P, Kozin ED, Hiesinger W, Woo YJ: Off-pump, minimally invasive and robotic coronary revascularization yield improved outcomes over traditional on-pump CABG. Int J Med Robot 2009, 5:1-12.

4. Warren OJ, Smith AJ, Alexiou C, Rogers PL, Jawad N, Vincent C, Darzi AW, Athanasiou T: The inflammatory response to cardiopulmonary bypass: part 1-mechanisms of pathogenesis. J Cardiothorac Vasc Anesth 2009, 23:223-231.

5. Warren OJ, Watret AL, de Wit KL, Alexiou C, Vincent C, Darzi AW, Athanasiou $\mathrm{T}$ : The inflammatory response to cardiopulmonary bypass: part 2anti-inflammatory therapeutic strategies. J Cardiothorac Vasc Anesth 2009, 23:384-393

6. Choi YS, Shim JK, Hong SW, Kim JC, Kwak YL: Comparing the effects of 5\% albumin and $6 \%$ hydroxyethyl starch 130/0.4 on coagulation and inflammatory response when used as priming solutions for cardiopulmonary bypass. Minerva Anestesiol 2010, 76:584-591.

7. Liou HL, Shih CC, Chao YF, Lin NT, Lai ST, Wang SH, Chen HI: Inflammatory response to colloids compared to crystalloid priming in cardiac surgery patients with cardiopulmonary bypass. Chin J Physiol 2012, 55:210-218.
8. Kuitunen AH, Hynynen MJ, Vahtera E, Salmenpera MT: Hydroxyethyl starch as a priming solution for cardiopulmonary bypass impairs hemostasis after cardiac surgery. Anesth Analg 2004, 98:291-297.

9. Tiryakioglu O, Yildiz G, Vural H, Goncu T, Ozyazicioglu A, Yavuz S: Hydroxyethyl starch versus Ringer solution in vardiopulmonary bypass prime solutions (a randomized controlled trial). J Cardiothorac Surg 2008, 3:45.

10. Yap WW, Young D, Pathi V: Effects of gelatine and medium molecular weight starch as priming fluid in cardiopulmonary bypass- a randomized controlled trial. Perfusion 2007, 22:57-61.

11. Shi XY, Zou Z, He XY, Xu HT, Yuan HB, Liu H: Hydroxyethyl starch for cardiovascular surgery: a systematic review of randomized controlled trials. Eur J Clin Pharmacol 2011, 67:767-782.

12. Akkucuk FG, Kanbak M, Ayhan B, Celebioglu B, Aypar U: The effect of HES $(130 / 0.4)$ usage as the priming solution on renal function in children undergoing cardiac surgery. Ren Fail 2013, 35:210-215.

13. Ertmer C, Wulf $\mathrm{H}$, Van Aken $\mathrm{H}$, Friederich P, Mahl C, Bepperling F, Westphal M, Gogarten W: Efficacy and safety of 10\% HES 130/0.4 versus $10 \%$ HES 200/0.5 for plasma volume expansion in cardiac surgery patients. Minerva Med 2012, 103:111-122.

14. Alavi SM, Ahmadi BB, Baharestani B, Babaei T: Comparison of the effects of gelatin, Ringer's solution and a modern hydroxyl ethyl starch solution after coronary artery bypass graft surgery. Cardiovasc J Afr 2012, 23:428-431.

15. Maesen B, Nijs J, Maesen J, Allessie M, Schotten U: Post-Operative Atrial Fibrillation: A Maze of Mechanisms. Europace 2012, 14:159-174

16. Guo Y, Lip GY, Apostolakis S: Inflammation in Atrial Fibrillation. J Am Coll Cardiol 2012, 60:2263-2270.

17. Friedrichs K, Klinke A, Baldus S: Inflammatory pathways underlying Atrial Fibrillation. Trends Mol Med 2011, 17:556-563.

18. Tian J, Lin X, Zhou W, Xu J: Hydroxyethyl starch inhibits NF-KappaB activation and prevents the expression of inflammatory mediators in Endotoxic Rats. Ann Clin Lab Sci 2003, 33:451-458.

19. Xie J, Lv R, Yu L, Huang W: Hydroxyethyl Starch 130/0.4 inhibits production of plasma Proinflammatory cytokines and attenuates nuclear factor-KappaB activation and Toll-Like receptors expression in Monocytes during Sepsis. J Surg Res 2010, 160:133-138.

doi:10.1186/1749-8090-8-71

Cite this article as: Gurbuz et al:: Hydroxyethyl starch 6\%, 130/0.4 vs. a balanced crystalloid solution in cardiopulmonary bypass priming: a randomized, prospective study. Journal of Cardiothoracic Surgery 2013 8:71.

\section{Submit your next manuscript to BioMed Central and take full advantage of:}

- Convenient online submission

- Thorough peer review

- No space constraints or color figure charges

- Immediate publication on acceptance

- Inclusion in PubMed, CAS, Scopus and Google Scholar

- Research which is freely available for redistribution 